\title{
PENERAPAN AUDIT KEPATUHAN PROSEDUR PENJUALAN KREDIT UNIT APARTEMEN
}

\author{
Cindy Mutiara Febyane ${ }^{1}$, Ratih Juwita ${ }^{2}$
}

Universitas Gunadarma

Email: cindymutiaraa@student.gunadarma.ac.id ${ }^{1}$, ratih_j@staff.gunadarma.ac.id ${ }^{2}$

\section{Abstrak}

Latar belakang: Audit kepatuhan merupakan pemeriksaan prosedur suatu organisasi dalam menentukan apakah organisasi tersebut menerapkan prosedur, peraturan, dan aturan khusus lainnya yang telah ditetapkan oleh otoritas tingkat tinggi.

Tujuan penelitian: Penulisan ilmiah ini bertujuan untuk menganalisis audit kepatuhan atas prosedur penjualan kredit (Studi Empiris pada Jasmine Park Apartment).

Metode penelitian: Alat analisis yang digunakan dalam penulisan ilmiah ini adalah analisis kualitatif deskriptif, yaitu analisis yang bertujuan untuk mmenjelaskan keadaan yang ada berdasarkan data yang telah dikumpulkan. Data penulisan ilmiah ini berupa data primer dan sekunder dalam bentuk skema, grafik, dan data penjualan Jasmine Park Apartment periode 2020.

Hasil penelitian: Hasil penulisan ilmiah ini menunjukkan bahwa Standar Operasional Prosedur (SOP) atas penjualan kredit unit apartemen sudah sangat baik walaupun ada beberapa poin yang tidak terpatuhi oleh karyawan divisi sales sehingga perlu adanya pengawasan dan pemantauan langsung.

Kesimpulan: Analisis hasil penelitian penerapan audit kepatuhan atas prosedur penjualan kredit unit apartemen Jasmine Park tahun 2020, penulis memperoleh hasil penerapan yang telah dipatuhi oleh karyawan Jasmine Park sebesar $87.5 \%$ yang berarti sangat kuat atau sangat baik namun belum sepenuhnya dilakukan oleh karyawan Jasmine Park Apartment

Kata kunci: Audit Kepatuhan, Prosedur Penjualan Kredit, Standar Operasional Prosedur

\section{Abstract}

Background: A compliance audit is an examination of the procedures of an organization in determining whether the organization is implementing procedures, regulations, and other special rules that have been set by a high-level authority.

The purpose of the study: Scientific writing aims to analyze compliance audits on credit sales procedures (Empirical Study at Jasmine Park Apartment).

Research method: The analytical tool used in scientific writing is descriptive qualitative analysis, which is an analysis that aims to explain the existing situation based on the data that has been collected. This scientific writing data is in the form of primary and secondary data in the form of schematics, graphs, and Jasmine Park Apartment sales data for the period 2020.

The results of the study: The results of this scientific writing indicate that the Standard Operating Procedure (SOP) for the sale of apartment unit loans is very good, although there are some points that are not adhered to by the sales division employees so that there is a need for direct supervision and monitoring.

Conclusion: Analysis of the results of research on the implementation of compliance audits on credit sales procedures for Jasmine Park apartment units in 2020, the authors obtained the results of implementation that have been complied with by Jasmine Park employees of $87.5 \%$ which means very strong or very good but not yet fully carried out by Jasmine Park Apartment employees.

Keywords: Compliance Audit, Credit Sales Procedure, Standard Operating Procedure

Diterima: 26-06-2021; Direvisi: 6-07-2021; Disetujui: 6-07-2021

How to cite:

E-ISSN:

Published by:
Cindy Mutiara Febyane, Ratih Juwita. (2021). Penerapan Audit Kepatuhan Prosedur Penjualan Kredit Unit Apartemen. Co-Value: Jurnal Ekonomi, Koperasi Kewirausahaan Vol12(2): 75-82 $\underline{\text { https://greenpublisher.id/ }}$ 


\section{PENDAHULUAN}

Perusahaan developer sebagai perusahaan yang bekerja untuk mengembangkan suatu kawasan permukiman menjadi tempat yang layak huni tentunya harus mempunyai Standar Operasional Prosedur (SOP) agar dapat menjalankan tugas seluruh divisi dalam sebuah perusahaan secara efisien. Jasmine Park Apartment adalah salah satu perusahaan developer yang menjual apartemen dengan pemandangan gunung, kota, dan kolam berenang.(KHAIRUNNISA, 2019) Perusahaan ini disibukkan dengan aktivitas penjualan unit apartemen dengan 3 jenis tipe apartemen yang berbeda dengan data penjualan 2020 sebagai berikut:

\section{Gambar 1 Data Penjualan Unit Apartemen Tahun 2020}

\begin{tabular}{ll}
\hline Tipe & Jumlah \\
\hline Studio & 58 \\
1 Bedroom & 7 \\
2 Bedroom & 18
\end{tabular}

Sumber: Data dari Supervisor Sales Jasmine Park

Berdasarkan hasil wawancara dengan supervisor sales Jasmine Park tahun 2020 terlihat bahwa data penjualan apartemen selama tahun 2020 terjual sebanyak 84 unit.(Rahman, 2022) Tipe unit studio merupakan unit yang paling banyak terjual sepanjang tahun 2020.(Prajogo \& Sastrawan, 2020) Tipe unit studio terjual sebanyak 58 unit, sedangkan untuk tipe 2 bedroom sebanyak 18 unit, dan yang paling sedikit adalah tipe 1 bedroom sebanyak 7 unit dari total penjualan.

Gambar 2 Data Metode Pembayaran Apartemen 2020

\begin{tabular}{cc}
\hline $\begin{array}{c}\text { Metode } \\
\text { Pembayaran }\end{array}$ & Jumlah \\
\hline Tunai Keras & $20 \%$ \\
Tunai Bertahap & $10 \%$ \\
Kredit & $70 \%$
\end{tabular}

Sumber: Data dari Supervisor Sales Jasmine Park

Berdasarkan Gambar 2, metode pembayaran yang paling banyak digunakan oleh konsumen adalah pembayaran secara kredit yaitu sebesar 70\%.(Sulistyowati et al., 2020) Dalam melakukan pembayaran kredit, Jasmine Park Apartment mengadakan kerjasama dengan Bank BNI, Bank OCBC, dan Bank BTN. Sedangkan untuk metode pembayaran cash keras sebesar 20\% dari total penjualan dan $10 \%$ secara cash bertahap.(Dewi \& Asliana, 2018) Maka dari itu, Standar Operasional Prosedur (SOP) harus benar-benar dilaksanakan karena aktivitas tersebut mendominasi jika dibandingkan dengan metode pembayaran lainnya.(Syifa, 2019)

\section{METODE PENELITIAN}

Objek penelitian pada penulisan ini adalah Prosedur Penjualan Kredit Unit Apartemen di Jasmine Park Apartment Bogor yang merupakan salah satu perusahaan pengembang (developer) yang menjual unit apartemen.(Pujiastuti et al., 2021) Jasmine Park Apartment bertempat di Jl. Letjen Ibrahim Adjie No.8, Ciherang, Dramaga, Bogor, Jawa Barat.

Jenis data yang digunakan pada penulisan ilmiah ini adalah jenis data yang bersifat kualitatif karena penulisan ilmiah ini tidak menggunakan data berupa angka namun 
berupa Standar Operasional Prosedur (SOP) yang menjadi acuan dari penulisan ini.(OPERASIONAL \& KOTA, n.d.) Sumber data pada penulisan ilmiah ini adalah data sekunder dan data primer.(Manting \& Sudarwanto, 2020)

Teknik dan alat analisis data yang digunakan adalah teknik analisis deskriptif kualitatif, yaitu sebuah teknik penelitian yang mempunyai tujuan untuk memberikan gambaran dan membahas secara sistematik dan akurat mengenai fenomena yang akan diteliti dengan cara mengumpulkan, mengklasifikasi, menganalisis, dan menginterpretasikan data dan fakta yang sudah diperoleh agar dapat menarik kesimpulan dan rekomendasi dengan cara membandingkan keadaan yang terjadi pada objek yang diteliti dengan teori yang relevan. Proses analisis ini juga digunakan secara bersamaan dengan proses pengumpulan data.(Budiasih \& Nyoman, 2014)

Audit kepatuhan karyawan terhadap Standar Operasional Prosedur (SOP) Penjualan Kredit Unit Apartemen di Jasmine Park dilakukan dengan menganalisa hanya pada kegiatan penjualan kredit oleh divisi marketing dengan Standar Operasional Prosedur (SOP) yang berlaku di Jasmine Park Apartment Bogor.

Berikut adalah buku dan jurnal yang penulis jadikan sebagai referensi dalam penulisan ilmiah ini:

1. Standar Operasional Prosedur (SOP) dan Akuntabilitas Kinerja Instansi Pemerintah.

2. Petunjuk Praktis Pemeriksaan Akuntan Publik.

3. Audit dan Jasa Asurans.

4. Jurnal Ilmiah Ecobuss

5. Jurnal Ilmu Akuntansi.

6. Jurnal Ekonomia.

7. Jurnal Ilmu dan Riset Akuntansi.

Teknik analisis yang digunakan dalam penulisan ilmiah ini adalah teknik analisis deskriptif kualitatif, yaitu analisis penelitian yang mempunyai tujuan untuk memberikan gambaran dan membahas secara sistematik dan akurat mengenai fenomena yang akan diteliti dengan cara mengumpulkan, mengklasifikasi, menganalisis, dan menginterpretasikan data dan fakta yang sudah diperoleh agar dapat menarik kesimpulan dan rekomendasi dengan cara membandingkan keadaan yang terjadi pada objek yang diteliti dengan teori yang relevan.(Nugrahani \& Hum, 2014) Dalam penulisan ilmiah alat analisis yang digunakan adalah kuesioner dengan metode Dean J. Champion.(Juita, 2014) Berikut ini hasil persentase responden metode Dean J. Champion:

1. Menghitung Persentase Responden

$$
\frac{\text { Jumlah Jawaban "Ya" }}{\text { Jumlah Jawaban Kuesioner }} \times 100 \%
$$




\section{HASIL DAN PEMBAHASAN}

\section{Tabel 3 Hasil Kuesioner}

\begin{tabular}{|c|c|c|c|c|}
\hline \multirow{2}{*}{ No } & \multirow{2}{*}{ Pernyataan } & \multicolumn{2}{|c|}{ Hasil } & \multirow{2}{*}{ Keterangan } \\
\hline & & Ya & Tidak & \\
\hline \multicolumn{5}{|c|}{ Kebijakan } \\
\hline 1 & $\begin{array}{l}\text { Melakukan pembayaran Booking Fee pada saat } \\
\text { pembuatan Form Pengajuan Kredit }\end{array}$ & $\mathrm{P}$ & & \\
\hline 2 & $\begin{array}{l}\text { Jika pengajuan kredit ditolak atau konsumen } \\
\text { membatalkan secara sepihak maka pihak sales } \\
\text { tidak mengembalikan Booking Fee }\end{array}$ & $\mathrm{P}$ & & \\
\hline 3 & $\begin{array}{l}\text { Pembeli melakukan pembayaran DP sebesar } 20 \% \\
\text { untuk pembayaran kredit }\end{array}$ & $\mathrm{P}$ & & \\
\hline 4 & $\begin{array}{l}\text { Melakukan survey kepada konsumen dari pihak } \\
\text { Jasmine Park }\end{array}$ & & $\mathrm{P}$ & Tidak selalu \\
\hline 5 & $\begin{array}{l}\text { Transaksi penjualan yang disetujui pimpinan } \\
\text { penjualan akan dibuatkan Surat Pemesanan } \\
\text { Apartemen (SPA) dan Pengikatan Perjanjian Jual } \\
\text { Beli (PPJB) }\end{array}$ & $\mathrm{P}$ & & \\
\hline 6 & $\begin{array}{l}\text { Jika konsumen terlambat dalam membayar maka } \\
\text { pihak Jasmine Park dapat mengenakan denda } \\
\text { sebesar } 0,1 \% \text { per hari dari jumlah pembayaran. }\end{array}$ & $\mathrm{P}$ & & \\
\hline 7 & $\begin{array}{l}\text { Jasmine Park memastikan bahwa konsumen } \\
\text { membayar BPHTB melalui notaris sebesar } \\
\text { "Harga Apartemen dikurangi Rp60.000.000 } \\
\text { dikalikan 5\%" }\end{array}$ & $\mathrm{P}$ & & \\
\hline \multicolumn{5}{|c|}{ Penerimaan Aplikasi Kredit Apartemen } \\
\hline 1 & $\begin{array}{l}\text { Divisi marketing meminta calon konsumen untuk } \\
\text { mengisi APK dan ditandatangani. }\end{array}$ & $\mathrm{P}$ & & \\
\hline 2 & $\begin{array}{l}\text { Calon konsumen membayarkan Booking Fee } \\
\text { sesuai tipe apartemen yang dipilih. }\end{array}$ & $\mathrm{P}$ & & \\
\hline 3 & $\begin{array}{l}\text { Calon konsumen menyerahkan berkas-berkas } \\
\text { secara lengkap paling lambat } 2 \text { minggu setelah } \\
\text { Booking Fee, jika tidak maka wajib di follow-up. }\end{array}$ & & $\mathrm{P}$ & $\begin{array}{l}\text { Tidak } \\
\text { Selalu }\end{array}$ \\
\hline 4 & $\begin{array}{l}\text { Memberikan opsi kepada konsumen untuk } \\
\text { mengubah cara bayar jika APK konsumen ditolak }\end{array}$ & & $\mathrm{P}$ & $\begin{array}{r}\text { Tidak } \\
\text { Selalu }\end{array}$ \\
\hline 5 & $\begin{array}{l}\text { Komite penjualan menandatangani SPA jika APK } \\
\text { telah disetujui. }\end{array}$ & $\mathrm{P}$ & & \\
\hline 6 & $\begin{array}{l}\text { Konsumen menandatangani SPA yang telah } \\
\text { ditandatangani oleh komite penjualan }\end{array}$ & $\mathrm{P}$ & & \\
\hline 7 & $\begin{array}{l}\text { Staff admin memberikan SPA rangkap pertama } \\
\text { kepada bank dengan berkas-berkas konsumen }\end{array}$ & $\mathrm{P}$ & & \\
\hline
\end{tabular}




\begin{tabular}{|c|c|c|c|}
\hline 8 & $\begin{array}{l}\text { Staff admin memberikan SPA rangkap kedua } \\
\text { diserahkan kepada konsumen dan ditukar dengan } \\
\text { APK yang dipegang oleh konsumen }\end{array}$ & $\mathrm{P}$ & \\
\hline 9 & $\begin{array}{l}\text { Staff admin menyimpan SPA rangkap ketiga } \\
\text { sebagai arsip beserta dengan fotocopy berkas- } \\
\text { berkas konsumen }\end{array}$ & $\mathrm{P}$ & \\
\hline 10 & $\begin{array}{l}\text { Staff admin memberikan SPA rangkap keempat } \\
\text { kepada bagian admin \& finance untuk diarsip } \\
\text { beserta semua tanda bukti penerimaan } \\
\text { pembayaran }\end{array}$ & $\mathrm{P}$ & \\
\hline 11 & $\begin{array}{l}\text { Staff admin melakukan follow-up ke konsumen } \\
\text { apabila konsumen tidak atau belum mengajukan } \\
\text { berkas-berkas ke kepada Jasmine Park lebih dari } \\
2 \text { minggu }\end{array}$ & $\mathrm{P}$ & \\
\hline 12 & $\begin{array}{l}\text { Divisi KPA \& Legal melakukan follow-up kepada } \\
\text { Loan Services Bank mengenai peluang untuk } \\
\text { lolos proses analisa dari Bank }\end{array}$ & $\mathrm{P}$ & \\
\hline 13 & $\begin{array}{l}\text { Divisi KPA \& Legal menyerahkan SP3K kepada } \\
\text { konsumen sebagai bahan pertimbangan sesuai } \\
\text { undangan yang telah dibuat }\end{array}$ & $\mathrm{P}$ & \\
\hline 14 & $\begin{array}{l}\text { Dalam persiapan akad, divisi KPA \& Legal } \\
\text { mengajukan persiapan pajak kepada bagian } \\
\text { finance. }\end{array}$ & $\mathrm{P}$ & \\
\hline 15 & $\begin{array}{l}\text { Divisi KPA \& Legal mempersiapkan berkas- } \\
\text { berkas konsumen yang akan dikirimkan kepada } \\
\text { notaris perihal membuat surat permohonan akad }\end{array}$ & $\mathrm{P}$ & \\
\hline 16 & $\begin{array}{l}\text { Divisi KPA \& Legal menyerahkan strata title dan } \\
\text { AJB kepada konsumen minimal } 2 \text { tahun setelah } \\
\text { serah terima }\end{array}$ & $\mathrm{P}$ & \\
\hline 17 & $\begin{array}{l}\text { Pihak developer meminta berkas untuk akad } \\
\text { kepada pihak bank yang akan diserahkan } \\
\text { bersamaan dengan serah terima unit }\end{array}$ & $\mathrm{P}$ & \\
\hline
\end{tabular}

\section{Pembahasan}

Berdasarkan Gambar 3 dapat dihitung persentase hasil kepatuhan kegiatan kerja dalam Standar Operasional Prosedur (SOP) Penjualan Kredit Apartemen sebagai berikut:

$$
\begin{aligned}
& \frac{\text { Jumlah Jawaban " } Y a^{\prime \prime}}{\text { Jumlah Jawaban Pertanyaan }} \times 100 \% \text {.............. } \\
& \qquad \frac{21}{24} \times 100 \%=87.5 \%
\end{aligned}
$$

Menurut Dean J. Champion (2013), jika hasil persentase kuesioner kepatuhan suatu prosedur 0\% sampai 25\% dapat dikatakan lemah (kurang baik), 26\%-50\% dapat dikatakan sedang, 51\%-75\% dapat dikatakan kuat (cukup baik), dan 76\%-100\% dapat dikatakan sangat kuat (sangat baik).(Yori, 2017) Dalam hal ini, hasil penelitian penulis adalah $87.5 \%$, dimana dapat dikatakan sangat kuat (sangat baik).(Yori, 2017) 


\section{Gambar 4 Hasil Persentase Tingkat Kepatuhan}

\begin{tabular}{|c|l|}
\hline Hasil Persentase & \multicolumn{1}{|c|}{ Keterangan } \\
\hline $0 \%-25 \%$ & Lemah (Kurang Baik) \\
$26 \%-50 \%$ & Sedang \\
$51 \%-75 \%$ & Kuat (Cukup Baik) \\
$76 \%-100 \%$ & Sangat Kuat (Sangat Baik) \\
\hline
\end{tabular}

Walaupun tingkat kepatuhan karyawan Jasmine Park sudah sangat baik, adapun pernyataan-pernyataan dari Standar Operasional Prosedur (SOP) yang tidak dilaksanakan setiap saat oleh karyawan Jasmine Park Apartment dilampirkan pada tabel berikut:

Gambar 5 Standar Operasional Prosedur (SOP) yang Tidak Terpatuhi

\begin{tabular}{|c|c|c|c|}
\hline No & Pernyataan & Penyebab & Rekomendasi \\
\hline 1 & $\begin{array}{l}\text { Melakukan } \\
\text { survey kepada } \\
\text { konsumen dari } \\
\text { pihak Jasmine } \\
\text { Park } \\
\end{array}$ & $\begin{array}{l}\text { Pihak sales atau broker sudah } \\
\text { mengetahui identitas dan latar } \\
\text { belakang dari calon konsumen } \\
\text { sehingga merasa yakin terhadap } \\
\text { kemampuan belinya. }\end{array}$ & $\begin{array}{l}\text { Sebaiknya pihak Jasmine Park } \\
\text { selalu melakukan survey guna } \\
\text { mengetahui latar belakang } \\
\text { calon konsumen secara pasti. }\end{array}$ \\
\hline 2 & $\begin{array}{l}\text { Calon konsumen } \\
\text { menyerahkan } \\
\text { berkas-berkas } \\
\text { secara lengkap } \\
\text { paling lambat } 2 \\
\text { minggu setelah } \\
\text { Booking Fee, jika } \\
\text { tidak maka wajib } \\
\text { di follow-up }\end{array}$ & $\begin{array}{l}\text { Pihak sales sudah berulang kali } \\
\text { menghubungi konsumen selama } 2 \\
\text { minggu pertama untuk segera } \\
\text { melengkapi berkas-berkas yang } \\
\text { diperlukan namun selalu } \\
\text { mendapatkan respon yang lambat } \\
\text { dari calon konsumen sehingga } \\
\text { terlambat. }\end{array}$ & $\begin{array}{l}\text { Sebaiknya pihak sales } \\
\text { melakukan timeline dalam } \\
\text { pengumpulan berkas dan } \\
\text { mengunjungi calon konsumen } \\
\text { sehingga berkas-berkas tidak } \\
\text { terlambat. }\end{array}$ \\
\hline 3 & $\begin{array}{l}\text { Memberikan opsi } \\
\text { kepada } \\
\text { konsumen untuk } \\
\text { mengubah cara } \\
\text { bayar jika } \\
\text { Aplikasi } \\
\text { Pengajuan Kredit } \\
\text { (APK) konsumen } \\
\text { ditolak }\end{array}$ & $\begin{array}{l}\text { Minim pengetahuan karyawan } \\
\text { tentang informasi bank yang } \\
\text { bekerjasama dengan Jasmine Park } \\
\text { sehingga sulit bagi pihak karyawan } \\
\text { Jasmine Park untuk } \\
\text { mengkomunikasikan informasi- } \\
\text { informasi tersebut kepada } \\
\text { konsumen dalam pengajuan } \\
\text { kreditnya di bank tersebut. }\end{array}$ & $\begin{array}{l}\text { Sebaiknya supervisor sales } \\
\text { mengadakan literasi rutin } \\
\text { mengenai update informasi } \\
\text { dan program bank yang } \\
\text { mengadakan kerjasama dengan } \\
\text { Jasmine Park kepada divisi } \\
\text { sales terkait dengan prosedur } \\
\text { penjualan agar peluang } \\
\text { penjualan maksimal. }\end{array}$ \\
\hline
\end{tabular}

Sumber: Penulis (2021)

Berdasarkan Gambar 5, terdapat tiga poin yang tidak terpatuhi yang dilakukan oleh divisi sales yang dapat mengurangi peluang untuk penjualan yang dilakukan oleh Jasmine Park Apartment. Secara umum, diperlukan penegasan kembali atas prosedurprosedur yang berlaku untuk menjaga konsistensi dalam bekerja dan menciptakan lingkungan kerja yang professional.(FADILAH, 2021) Apabila pihak sales dapat meminimalisir 3 Standar Operasional Prosedur (SOP) tersebut, otomatis produktivitas penerimaan dari hasil penjualan apartemen Jasmine Park juga mengalami peningkatan. Selain itu, perlu adanya pengendalian internal yang melakukan pengawasan terhadap 
ketepatan sales dalam melakukan pekerjaannya sesuai dengan Standar Operasional Prosedur (SOP) sebagai wujud pertanggungjawaban kepada manager sales dan supervisor sales.(Agustina, 2021)

\section{KESIMPULAN}

Analisis hasil penelitian penerapan audit kepatuhan atas prosedur penjualan kredit unit apartemen Jasmine Park tahun 2020, penulis memperoleh hasil penerapan yang telah dipatuhi oleh karyawan Jasmine Park sebesar $87.5 \%$ yang berarti sangat kuat atau sangat baik namun belum sepenuhnya dilakukan oleh karyawan Jasmine Park Apartment. Ada beberapa poin dari Standar Operasional Prosedur (SOP) penjualan kredit yang tidak terpatuhi diantaranya adalah karyawan tidak melakukan survey kepada konsumen dari pihak Jasmine Park dikarenakan pihak sales atau broker sudah mengetahui identitas dan latar belakang dari calon konsumen sehingga merasa yakin terhadap kemampuan belinya. Lalu, adanya ketidakpatuhan dalam melakukan pengumpulan berkas-berkas konsumen tepat waktu sehingga lewat dari waktu yang telah ditentukan yaitu 2 minggu yang disebabkan oleh respon yang lambat dari konsumen. Kemudian, pihak sales terkadang tidak selalu memberikan opsi kepada konsumen untuk mengubah cara bayar apabila Aplikasi Pengajuan Kredit (APK) konsumen ditolak dikarenakan minimnya pengetahuan karyawan dalam program-program ter-update dari tiap-tiap bank yang melakukan kerjasama dengan Jasmine Park. Apabila ketiga poin Standar Operasional Prosedur (SOP) tersebut dapat diminimalisir, maka produktivitas dari penjualan Jasmine Park diharapkan dapat meningkat di periode yang akan datang.

\section{BIBLIOGRAFI}

Agustina, D. (2021). Analisis Penerapan Standar Operasional Prosedur (SOP) Dalam Meningkatkan Kualitas Kerja Karyawan Bengkel Auto Dakar Ponorogo. IAIN PONOROGO.

Budiasih, I., \& Nyoman, G. A. (2014). Metode Grounded Theory dalam riset kualitatif. Jurnal Ilmiah Akuntansi Dan Bisnis, 9(1), 19-27.

Dewi, D. N., \& Asliana, E. (2018). PERHITUNGAN TITIK IMPAS (BREAK EVEN POINT) DENGAN METODE MARGIN KONTRIBUSI SEBAGAI ALAT PERENCANAAN LABA PADA PT YOENIKA DARMA PERSADA. Karya Ilmiah Mahasiswa.

FADILAH, N. U. R. S. (2021). PENGARUH PEMAHAMAN AKUNTANSI, PEMANFAATAN SISTEM INFORMASI AKUNTANSI KEUANGAN DAERAH DAN PERAN INTERNAL AUDIT TERHADAP KUALITAS LAPORAN KEUANGAN PEMERINTAH KOTA TEGAL (STUDI KASUS DI BAKEUDA PEMERINTAH KOTA TEGAL). Universitas Pancasakti Tegal.

Juita, R. K. (2014). Analisis akuntansi pertanggungjawaban: Studi kasus pada PT. PLN Persero Tanjungpinang. Jurnal Akuntansi, Maret.

KHAIRUNNISA, F. (2019). LAPORAN PRAKTIK KERJA LAPANGAN PADA BAGIAN PENGEMBANGAN SUMBER DAYA MANUSIA DI PERUM PERUMNAS.

Manting, L., \& Sudarwanto, P. B. (2020). The Implementasi Standar Operasional Prosedur Penyelenggaraan Pendidikan di Lembaga Pembinaan Khusus Anak (LPKA) Tangerang. Jurnal Madani: Ilmu Pengetahuan, Teknologi, Dan Humaniora, 3(2), 196-201.

Nugrahani, F., \& Hum, M. (2014). Metode penelitian kualitatif. Solo: Cakra Books, 1(1). 
OPERASIONAL, I. K. P. S., \& KOTA, P. B. O. P. D. (n.d.). PROGRAM STUDI ILMU PEMERINTAHAN FAKULTAS ILMU SOSIAL DAN ILMU POLITIK UNIVERSITAS BRAWIJAYA.

Prajogo, S. A., \& Sastrawan, A. (2020). EFEKTIVITAS DAN EFISIENSI LUASAN, PENZONAAN, SIRKULASI INTERNAL, DAN RUANG GERAK PADA UNIT APARTEMEN TIPE 2 KAMAR TIDUR. Riset Arsitektur (RISA), 4(02), 120-137.

Pujiastuti, N. A., Nailah Firdausiy, S. T., \& Yudon, A. (2021). Pengembangan Kawasan Terminal Baranangsiang Menuju Implementasi Transit Oriented Development (TOD). Universitas Brawijaya.

Rahman, A. (2022). PROSEDING TEKNOLOGI LABORATORIUM.

Sulistyowati, R., Paais, L., \& Rina, R. (2020). Persepsi Konsumen Terhadap Penggunaan Dompet Digital. ISOQUANT: Jurnal Ekonomi, Manajemen Dan Akuntansi, 4(1), $17-34$.

Syifa, L. (2019). Pengaruh kemudahan penggunaan mobile banking terhadap perilaku konsumtif mahasiswa FITK UIN Syarif Hidayatullah Jakarta. Jakarta: Fakultas Ilmu Tarbiyah Dan Kejuruan UIN Syarif Hidayatullah.

Yori, M. (2017). Efektivitas Peranan Audit Internal dalam Pengendalian Kas pada Hotel Parai Montain Resort Bukittinggi”.

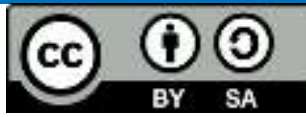

This work is licensed under a Creative Commons Attribution-ShareAlike 4.0 International License 